\title{
Topology Optimization for Additive Manufacturing as an Enabler for Light Weight Flight Hardware
}

\author{
Melissa Orme ${ }^{1, *} \mathbb{C}$, Ivan Madera ${ }^{1}$, Michael Gschweitl ${ }^{2}$ and Michael Ferrari ${ }^{2}$ \\ 1 Morf3D Inc., El Segundo, CA 90245, USA; ivan@morf3d.com \\ 2 Ruag Space, 8052 Zürich, Switzerland; michael.gschweitl@ruag.com (M.G.); michael.ferrari@ruag.com (M.F.) \\ * Correspondence: melissa@morf3d.com; Tel.: +1-310-607-0188
}

Received: 24 September 2018; Accepted: 19 November 2018; Published: 25 November 2018

\begin{abstract}
Three case studies utilizing topology optimization and Additive Manufacturing for the development of space flight hardware are described. The Additive Manufacturing (AM) modality that was used in this work is powder bed laser based fusion. The case studies correspond to the redesign and manufacture of two heritage parts for a Surrey Satellite Technology LTD (SSTL) Technology Demonstrator Space Mission that are currently functioning in orbit (case studies 1 and 2), and a system of five components for the SpaceIL's lunar launch vehicle planned for launch in the near future (case study 3). In each case, the nominal or heritage part has undergone topology optimization, incorporating the AM manufacturing constraints that include: minimization of support structures, ability to remove unsintered powder, and minimization of heat transfer jumps that will cause artifact warpage. To this end the topology optimization exercise must be coupled to the Additive Manufacturing build direction, and steps are incorporated to integrate the AM constraints. After design verification by successfully passing a Finite Element Analysis routine, the components have been fabricated and the AM artifacts and in-process testing coupons have undergone verification and qualification testing in order to deliver structural components that are suitable for their respective missions.
\end{abstract}

Keywords: additive manufacturing; topology optimization; design for additive manufacturing; 3D printing; aerospace; full-life cycle manufacturing flow

\section{Introduction}

Additive Manufacturing, or AM, is the potentially disruptive manufacturing technology in which a structural component is fabricated layer by layer via digital information. It is termed 'Additive' because material is added to every cross sectional layer, as opposed to 'Subtractive' in which material is removed from a raw stock. The aerospace industry is an industrial sector that has much to gain from Additive Manufacturing [1]. Fabricating structural components layer by layer from digital information provides the benefits of: increased design freedom, including the ability to exploit the results of topology optimization algorithms to significantly lightweight parts; eliminating system part count by consolidating assemblies into fewer parts; reducing the lifecycle time between concept, design, manufacture, and validated component delivery; and, a buy-to-fly ratio that approaches unity, thereby leading to significant raw material cost savings as well as leaving a positive environmental impact. Moreover, AM also has the ability to incorporate added functionality, such as internal cooling channels and thermowells into components; manufacture highly complex geometries that would be impossible or very difficult to be realized with traditional methods; and, to combat component obsolescence by fabricating on demand [2].

This paper discusses the design for Additive Manufacturing of light-weight, topologically optimized components that are intended for spaceflight, and will focus on three illustrative examples: 
the first two of which are currently found on an orbiting SSTL satellite [3], and the third that is an engine support structure for a lunar launch vehicle [4]. Because the components must be qualified for flight, the designs are verified by rigorous Finite Element Modeling analyses. Subsequently, the Additively Manufactured artifacts and in-process witness coupons undergo materials and mechanical testing in order to verify the required microstructural characteristics and mechanical properties. Because Additive Manufacturing considerations, such as the minimization of overhangs, encapsulated powder, and heat accumulation are not included in the topology optimization formulations that are presented in this work, a subsequent Finite Element Modeling is necessary because the aforementioned considerations are incorporated manually in the topology optimization routine with significant 'human-in-the-loop' iterative analysis. The manual step also includes incorporating allowances for tool access, assembly, fixturing, and application of testing sensors, which are refinements that could occur for any mode of manufacturing (e.g., traditional or AM).

\section{Background}

The past decade has seen the technology of Solid Freeform Fabrication, a term that was coined in 1987 to describe the fabrication of structural freeform components directly from a computer model without part-specific tooling [5], gain considerable traction in industry. Currently, the term 'Additive Manufacturing' has evolved to generally describe the technologies, such as Solid Freeform Fabrication, which strives to build functional components layer-by-layer from digital information, and includes powder bed fusion processes, wire deposition, and directed energy deposition [6]. Its traditional counterpart, 'Subtractive Manufacturing', encompasses conventional manufacturing methods in which material is successively removed from a bulk with methods such as $\mathrm{CNC}$ machining in order fabricate a structural component.

One of the more successful technologies of AM is that of Selective Laser Melting, which is a powder bed fusion process $[7,8]$, as illustrated schematically in Figure 1 . The main elements of the Selective Laser Melting process are a leveled bed of metal powder and a focused laser beam that scans the surface of the powder bed according to a digital representation of the desired component, causing localized melting and subsequent rapid solidification. The CAD file of the desired part is converted into an STL file and is subsequently 'sliced' into thin cross-sectional layers. Once the laser scans a layer of powder according to the sliced STL file, the powder bed is physically lowered (indicated by the downward orange arrow) a selectable distance in the range of 30-90 microns [1.2-3.5 thousandths of an inch], and a new layer of powder is swept onto the top of the powder bed from the powder dispenser by the recoater blade. The laser beam then scans the new layer with information corresponding to the new geometrical slice and the process is repeated until the three-dimensional (3D) component is fabricated and contained within the lowered powder bed. To retrieve the fabricated component, the powder bed is then raised and excess powder is removed and sieved for recycling if the specific Additive program allows for using recycled powder. It has been shown experimentally that there are no significant differences in elemental concentrations between virgin powder and that recycled powder after eight builds [9]. However, in many cases, flight-worthy hardware is required to be fabricated from virgin powder, leaving the recycled powder to be used for prototypes. More detailed descriptions of Additive Manufacturing can be found elsewhere [10-15]. An important consequence of Selective Laser Melting is that due to the 'selective', or localized aspect of the melting and subsequent rapid solidification, the resulting microstructure is significantly refined [16], leading to enhanced mechanical properties, such as ultimate strength and yield strength [17].

The enhanced mechanical properties inherent to rapid solidification that are associated with laser based fusion are reduced, however, if the fabricated part is subjected to subsequent heat treatment, which is often employed in an effort to remove internal residual stresses that accumulate due to the anisotropy of the heat transfer associated with Additively Manufactured components [18-20]. For this reason, it is important to consider heat transfer issues in the design phase, which is intrinsically coupled 
with the orientation of the layerwise build in an effort to reduce, when possible, anisotropy of heat transfer that is associated with the building phase of the part fabrication.

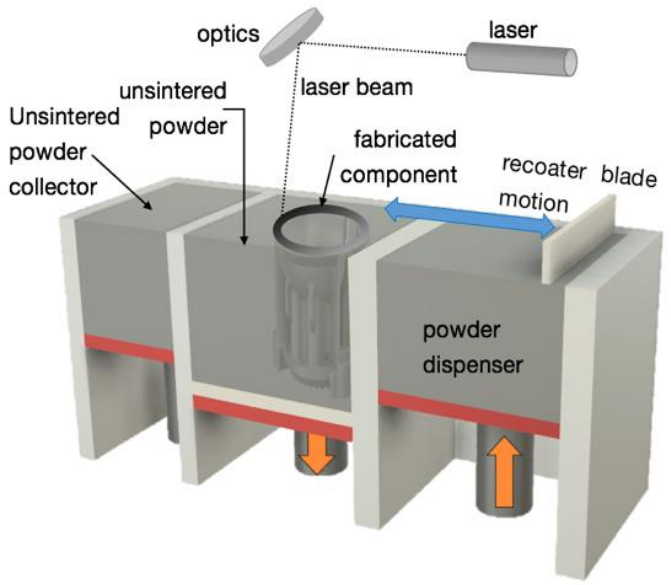

Figure 1. Conceptual schematic of powder bed laser Additive Manufacturing.

Additionally, it is often wrongly assumed that Hot Isostatic Pressing (HIP) need be performed on aluminum alloys in an effort to reduce porosity within powder bed fusion components. Performing HIP on the components will result in even further reductions in strength than stress relieving treatments. It should be noted that all AlSi10Mg components that are reported in this work have an as-built (un heat-treated or post processed) density of $99.7 \%$ or higher, which corroborates other literature values of of $99.8 \%$ [21], making the need for HIP for the purpose of reducing porosity in AlSi10Mg components moot.

\section{Holistic Process Flow}

In order to Additively Manufacture components that are worthy of spacecraft or aircraft flight, it is necessary that they be created with reliable and repeatable mechanical and material properties. To this end, a holistic process flow has been developed and established to ensure reliable and repeatable AM parts. The holistic process flow, which is illustrated in Figure 2 includes: candidate part selection; topology optimization for Additive Manufacturing, including AM design considerations (e.g., support structure removal, powder removal, minimization of residual stresses through support structure design, and part design); finite element modeling for analytic verification; AM fabrication of the artifacts and in-process testing coupons; and, final verification at both coupon and component levels. With two separate feedback loops, the holistic process-flow includes verification steps that are incorporated to insure that: (a) the optimized design can withstand the specified loading conditions (first feedback loop) and (b) the mechanical integrity and performance of the manufactured component is suitable for conditions in which it will be employed (second feedback loop). The process flow is discussed in more detail elsewhere [3,4,22]. Note that the topology optimization routine that is employed in this work is the commercially available Altair Hyperworks software package, which, at the time of this work, did not include the AM considerations described above, and hence these are included in manual iterative loops. The holistic process flow refers not to the Topology Optimization exercise, but rather to the entire flow from candidate part selection to verification for flight.

\subsection{Candidate Part Selection}

Because a component can be additively manufactured does not mean that it is necessarily suitable. To benefit from Additive Manufacturing, added value should be found in terms of reducing weight, manufacturing lead time, part consolidation, added functionality, added complexity, or combating obsolescence. Not all flight components are suitable for Additive Manufacturing. The case studies that 
are discussed in this chapter have been identified as suitable candidates for Additive Manufacturing due to the fact that they will be significantly lighter in weight than their subtractive counterparts, and will be fabricated on a rapid timescale (concept to validation in eight weeks). The test cases presented have been purposely selected because they have the potential to experience significant weight reductions over their nominal counterparts. Not all AM topologically optimized designs will experience the same weight reduction.

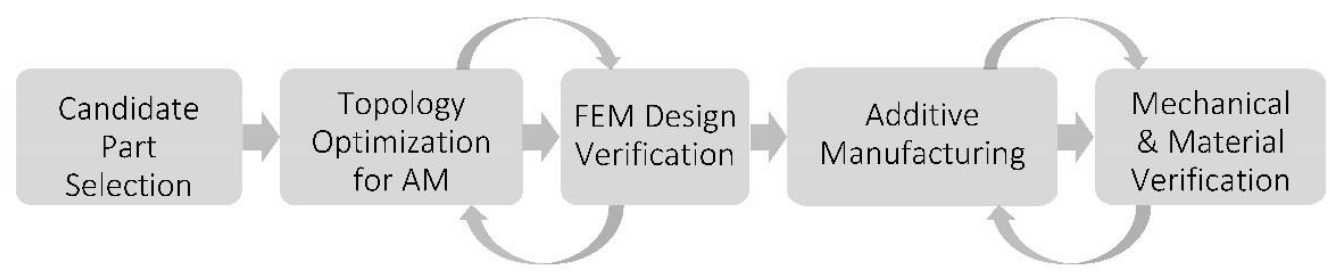

Figure 2. Holistic Process Flow for the fabrication of repeatable AM components.

\subsection{Topology Optimization for Additive Manufacturing}

The discipline of topology optimization has been used in industry for over two decades [23] and it describes a mathematical method to determine the optimum distribution of material in a design space for a given set of loading and boundary conditions. Early application of topology optimization was found on General Motors Powertrain for under hood brackets [24] and was utilized with subtractive manufacturing.

Until recently, manufacturing constraints limited the utilization of topology optimization because conventional manufacturing could not always produce a topologically optimized component. The advent of AM, however, has revealed renewed interest in the discipline of topology optimization, because many topologically optimized components can now be made with AM that were not possible otherwise $[25,26]$.

Because the topology optimization exercise removes material from all locations where it is not necessary to support the specific loads or satisfy specific boundary conditions, resulting components often contain structures that are not constant in cross section and resemble tree branches or bones, and hence, are termed 'bionic' or 'organic'. The fabrication of hollow structures, structures with internal cooling channels, organic, bionic shaped structures, and structures filled with lattice elements [27] can now be made via Additive Manufacturing.

An important aspect of the topologically optimized design for Additive Manufacturing is to create self-supporting components, or when not possible, components with the minimal number of support structures. Support structures are those sacrificial elements that are incorporated into the component build that support low angled members with respect to the build plane. A good rule of thumb is that members or components greater than 45 degrees from the build plate platform can be printed without support structures. Angles as low as 27 degrees have also been achieved depending on the aspect ratio of the member in question. Hence the designs are driven in part by component orientation with respect to build direction to ensure minimal support structures. Additionally, support structures may be added to mitigate thermal effects that can be detrimental for certain geometries. Hence, design efforts focus on creating approximately uniform member cross sections in an effort to achieve nearly homogeneous heat transfer towards the base plate, thereby minimizing the occurrence of thermal related warping. Furthermore, since downward facing surfaces are known to exhibit inferior characteristics in terms of surface quality and hence dynamic performance, these regions not chosen for highly loaded areas. Downward facing surfaces, termed 'downskins', are typically more rough than the upward facing surfaces due to the fact that those surfaces are in contact with unmelted powder, whereas upskins are in contact with a solid. Because heat conduction through a powder is different than that of a solid, the phase change characteristics of those two regions are markedly different, resulting in different surface textures. The relatively rough downskins can be improved, however, by altering the processing 
parameters (e.g., laser power, speed, and hatch separation) in the downskin regions to account for the less efficient heat conduction through the powder.

In this work, all topology optimization efforts were conducted in collaboration with RUAG Space and were employed with Altair's Hyperworks 14.0 software suite in order to determine the optimum placement of material with respect to the specific loading and geometric requirements. In order to set-up the topology optimization exercise, interface locations (locations where the part is mounted to the spacecraft or another unit is mounted to the part), as well as stay-in volumes and non-design zones are specified to obtain a resulting design volume. The stay-in volume is the envelope in which the part needs to remain in order to avoid interference with neighboring components on the spacecraft or to allow suitable clearance for part integration or tool access. Non-design zones correspond to fixed regions where material must remain and may correspond to attachment points, or other inherent features of the component. The resulting design space (stay-in volume minus non-design space) is a volume in which the topology optimization algorithm decides where material is needed to fulfill the structural requirements of the part.

Additive Manufacturing considerations that arise due to the layerwise fabrication, such as geometric distortion due to thermal jumps, anisotropic heat accumulation as a function of component geometry coupled with laser scanning regime, the need to support overhanging members, and the need to remove unsintered powder are not intrinsically included in the topology optimization formulations presented herein, however they are considered through manual 'human-in-the-loop' iterations.

Several exciting works have focused on including the AM constraints, such as support structure elimination (through overhang elimination) in topology optimization routines and are included in references [28-36]. Additionally, Liu et al. [37] recently presented a review paper on recent trends and future challenges that are associated with the incorporation of AM constraints and considerations into topology optimization algorithms. The aforementioned references are computational in nature, focused on the development of valid topology optimization routines for AM, and do not focus on the full value-stream of additive manufacturing.

\subsection{FEM Design Verification}

All analysis and optimization in this work was performed with Altair's Hyperworks 14.0, which uses Hypermesh as pre-processor, OptiStruct as solver, and Hyperview for post-processing. A convergence study was not carried out in this work; however, the results are validated through a material test campaign that is the final step of the holistic process flow and is described in subsequent sections of this work. The material is Additively Manufactured aluminum alloy AlSi10Mg, which is assumed to behave as a linear elastic material. The material properties from previous AM material characterization studies have been employed in this effort.

The mesh size in the analysis has been constrained to be relatively small in order to properly assess stress concentrations (approximately 1 million elements and around 300,000 Nodes, with a mesh size of approx. 1.2-2.5 mm [47-98 thousandths of an inch]). The AM parts are modeled with solid elements (tetra).

Due to the fact that Additive Manufacturing is still a relatively new process and it lacks a heritage database from which to draw, highly conservative design allowables were used. Moreover, in addition to the usual safety factors employed for developing space products, an AM Conservatism Factor of 1.5 has also been incorporated, which allows for a 'comfort zone' to compensate for its lack of heritage data.

The Margin of Safety (MoS) of the part is calculated according to the formula below:

$$
M o S_{\text {yield }}=\frac{\sigma_{\text {allw, }, \text { AlSi10 }}}{\sigma_{\text {vonMises }} \cdot S F_{\text {yield }} \cdot S F_{A M}}-1
$$

where $\sigma_{\text {allw, AlSi10Mg }}$ is the maximum allowable yield stress (design allowable), $\sigma_{\text {vonMises }}$ is the Von Mises stress obtained from FEM analysis, $S F_{\text {yield }}$ is the yield strength safety factor, and $S F_{A M}$ is the 
Additive Manufacturing conservatism safety factor. Equation (1) is used in subsequent sections to derive the Margin of Safety for each of the case studies presented.

\subsection{Additive Manufacturing}

All of the components in this paper were fabricated on an EOS M290 machine housed at Morf3D in El Segundo, California, which has a maximum power output of $370 \mathrm{~W}$, and were built with a 30-micron layer thickness. The build plate was elevated to $165 \mathrm{C}$ in an effort to mitigate internal residual stresses and to eliminate the need for subsequent heat treatment, which reduces the mechanical values considerably. The material used was virgin AlSi10Mg powder characterized with D10, D50, and D90 values of $22.7,41.8$, and 69.8 microns, respectively. For clarity, D10 is the diameter at which $10 \%$ of the powder's mass is comprised of particles with a diameter less than this value, and so on for D50 and D90. The additive manufacturing environment was flushed with argon gas. Materialise Magics software was used to prepare the data and to generate support structures. EOSPRINT software was used to design and optimize build parameters.

Five Vertical and five horizontal tensile coupons, three density cubes, and three thin walled hermetically sealed powder archival components were added to each build plate along with the desired artifacts.

\subsection{Mechanical and Material Verification}

The next step in the holistic process flow is Testing. None of the components in this work required subsequent heat treatment due to the fact that they were built with an elevated build plate temperature of $165 \mathrm{C}$. Hence the coupons were cut from the build plate with a wire EDM, and were sent directly to the testing laboratory. The co-fabricated coupons are tested for Ultimate Tensile Strength, Yield Strength, Elongation, and density, and their values must be greater than or equal to the acceptance allowables imposed by the customer.

After removing the components from the build plate with the wire EDM, their support structures were removed, and all accessible surfaces were media blasted. Further, attachment points and mating surfaces were machined to achieve the tolerances required for their function. The components or component assembly (e.g., case study 3 ) were subjected to vibration testing consisting of a combination of the following: low level sine, sine dwell, and random vibration.

In addition to structurally testing the components, each component was scanned via Computed Tomography (CT) in order to identify the internal pores, inclusion, or cracks within the resolution of the CT scanner.

Additionally, a 3D model of the fabricated components was generated with the CT scan data and compared to the nominal CAD file from which it was fabricated. A comparison of the two files was used to generate a heat map illustrating any geometric deviations as compared to the allowables set forth from the customer.

\section{Case Studies}

Three case studies are discussed that offer different insights into topology optimization. The heritage geometry of the first case study is illustrated in Figure 3, which is a Star Tracker Camera Bracket employed in SSTL's Technology's mission. The heritage design was machined out of titanium bulk. The constraints for this case study were that the attachment points remain fixed and that the design space could not extend further than the limits that were illustrated by the geometrical faces, however the bounding planar faces need not be preserved.

Figure 4 illustrates the second case study that is an edge insert also used in the SSTL Technology mission. It is apparent that the pictured geometry could be fabricated with subtractive means. Hence, in order to make this a suitable candidate part for AM, this case study sought to significantly lightweight the component as compared to its heritage counterpart. For this case, the boundary conditions specified are that the orthogonal faces are required to be preserved as they act as mating 
surfaces to the satellite sandwich panels. The material internal to the faces, however, is free to be redistributed through topology optimization. For the purpose of redistributing the material internal to the geometric faces, two critical design issues were needed to be addressed: (a) eliminate the need for internal support structures, since they would not be removable in the enclosed space and (b) create a way to remove the unprocessed powder.

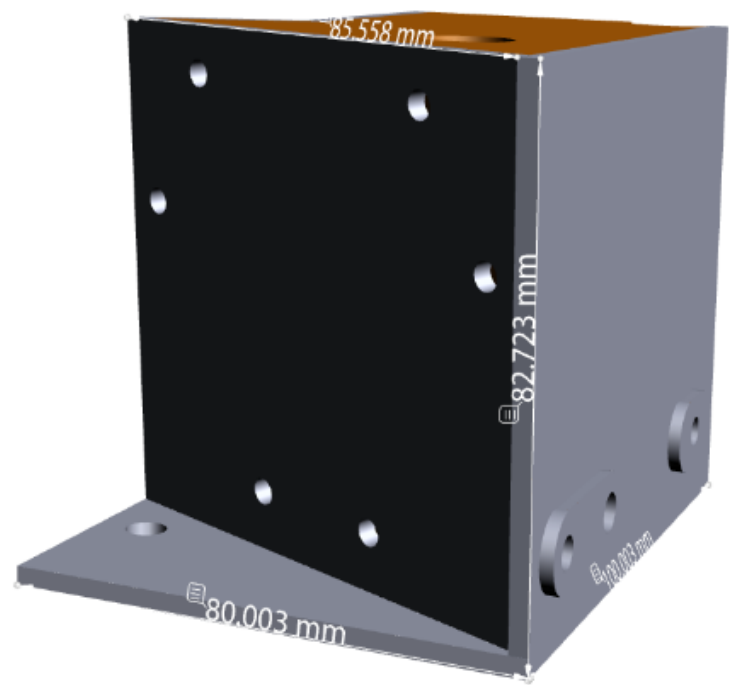

Figure 3. Nominal star tracker camera bracket.

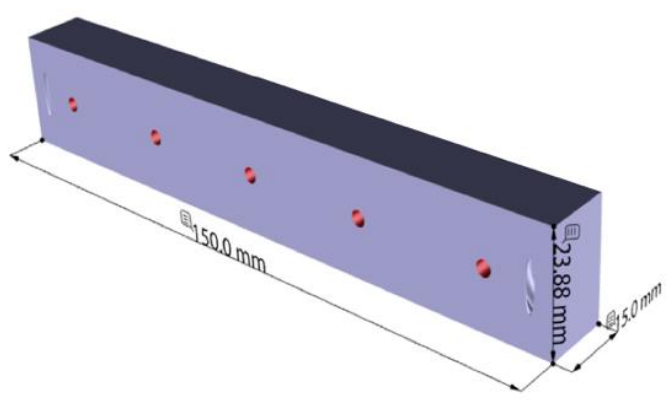

Figure 4. Nominal insert design geometry.

Figure 5 illustrates the nominal geometry of the third case study, which is a system of five parts that are assembled as one part. It serves as a thruster mount for a lunar vehicle intended for launch in the near future as part of SpaceIL's lunar mission. Once assembled it spans $800 \mathrm{~mm}$ in diameter and approximately $280 \mathrm{~mm}$ in height. It was chosen as a demonstration of topology optimization of an assembly of parts.

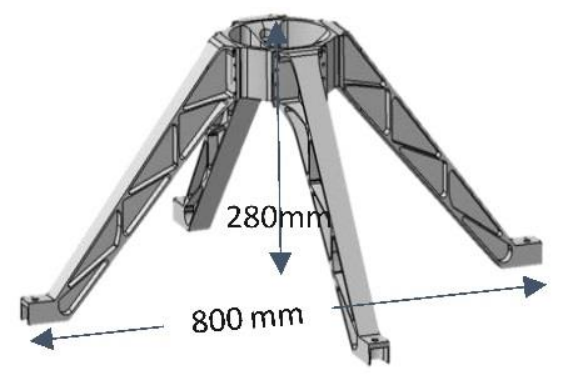

Figure 5. Nominal Lunar Lander engine mount.

The objective set for our optimization routine in each case is to minimize mass while remaining simultaneously compliant to stiffness requirements and maximum applied stress levels that are 
appropriate to each application. The case study examples are illustrative of the advantages of the union of topology optimization with Additive Manufacturing.

\section{Results}

The design, utilizing topology optimization (with the manual incorporation of the AM manufacturing considerations); FEM analysis, manufacture; and, testing results for the three case studies pictured in Figures 3-5 are discussed in detail below in the context of the holistic process flow. Each case study was selected for discussion in this work because they offer different topology optimization constraints.

\subsection{Case Study 1: Star Tracker Camera Bracket}

Case Study 1 presents the topology optimization example in which the material is free to move within the design space, and the boundaries of the design space (with the exception of the attachment points) need not coincide with the boundaries of the final part.

\subsubsection{Topology Optimization}

The design space for the Star Tracker Camera Bracket is illustrated in Figure 6. The geometry for the fixed interface points were taken from the CAD file. The design space was meshed with a mesh element size of $2 \mathrm{~mm}$, and subsequently with $0.75 \mathrm{~mm}$ for refined analysis. The OptiStruct optimization routine was employed, with the material being given the freedom to be located anywhere within the design space. With the exception of the attachment points, the external boundaries of the design space are not required to be incorporated into the optimized part.

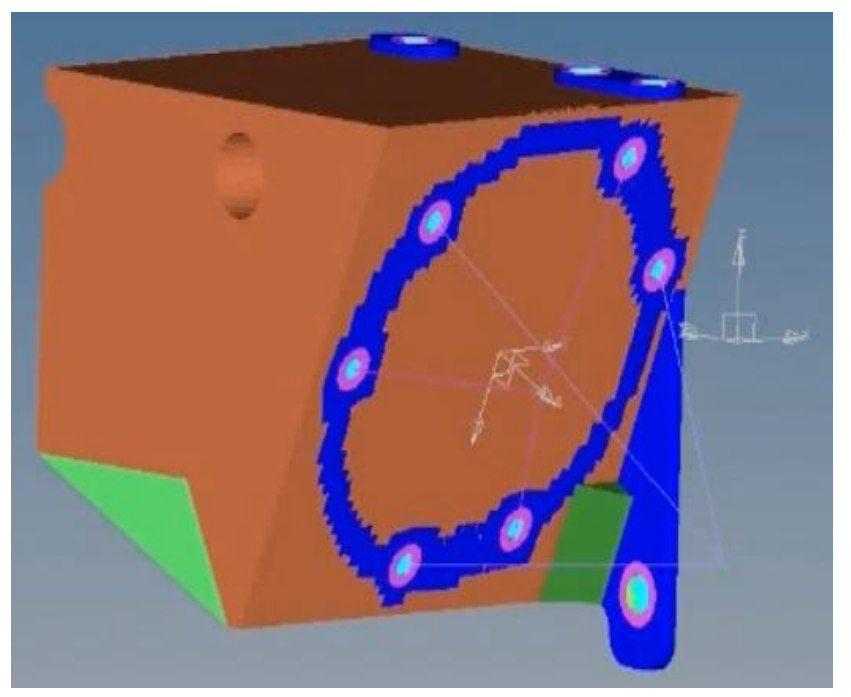

Figure 6. Design space for the Star Camera Bracket Topology Optimization Routine.

A minimum and maximum member thickness as 6 and $20 \mathrm{~mm}$, respectively, was implemented. Other design constraints imposed that were within the topology optimization routine were a maximum stress of $125 \mathrm{MPa}$, and frequency constraint that the first eigenfrequency be greater than $140 \mathrm{~Hz}$ with a factor of safety of 1.3. The build orientation was determined by the engineer, and, once established, the other Additive Manufacturing constraints were considered by the engineer through manual iterations. To be self-supporting, care was taken to insure that no component grew at an angle less than 45 degrees with respect to the build plate, and efforts to minimize large volumetric jumps that would otherwise cause thermal jumps and subsequent component warping were also incorporated. Intermediate design results were interpreted and Poly-NURBs based software was employed to create a printable design. 


\subsubsection{FEM Design Verification}

The final optimized design of the Tracker Camera bracket was subjected to a Finite Element Modeling campaign, as described in Figure 2, which serves as a redundant check that the final design will perform according to the loads prescribed. This constitutes the first verification cycle of the holistic process flow. If the topology optimized design fails the Finite Element Analysis, the design is modified by adding or redistributing mass and the design is analyzed again until it passes the FEM Design verification step. This is a necessary component in the holistic process flow because manual steps are incorporated into the topology optimization routine to account for the minimization of support structures, tool access, and other practical issues that are associated with manufacturing and assembly.

For the Star Tracker Camera bracket, RBE2 elements were used for each attachment point. Accelerations were implemented for each global axis of the satellite with $120 \mathrm{~g}_{\text {peak. }}$. Eigen frequencies in the range of 1-100 were calculated with the design restriction that the first eigenfrequency be greater than $140 \mathrm{~Hz}$.

Figure 7 illustrates the results of the FEA analysis for the Star Tracker Camera bracket. Except for one attachment point (indicated by the blue arrow), all von Mises stresses were found to be below $110 \mathrm{MPa}$, well within the factor of safety.

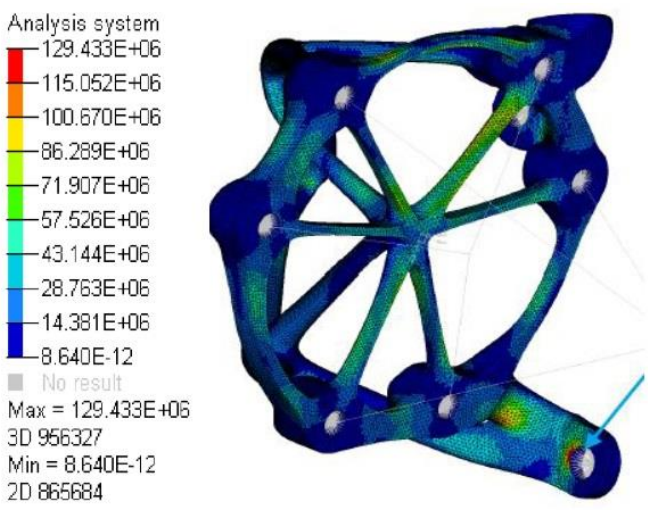

Figure 7. Results of FEM simulation analysis.

The maximum stress resulting from the model at the indicated attachment point is larger than the physical realization would be because the modeled bolt connection assumed that all nodes of the inner borehole were clamped along all six degrees of freedom. In the physical situation, however, a washer would clamp the part on one side of the attachment point and on the opposite side the part would be clamped to the spacecraft structure. Hence, a more realistic situation would require the modeling of the washer and implementing contact definitions, yielding a lower calculated stress. Because the focus of this project was not focused on FEM modeling of the component connections, but it is used as a guide to indicate the soundness of our topology optimization results, we chose to approximate the modeling of the connection point, as described. The soundness of the fabricated parts is subsequently validated through proof testing as described in further studies. Furthermore, the assumed material yield limit that is employed in the analysis of $190 \mathrm{MPa}$ is also conservative, as testing of the manufactured witness coupons resulted in average values of $244.9 \mathrm{MPa}$ and $208.5 \mathrm{MPa}$ for horizontally and vertically grown coupons, respectively (see tensile testing below, Table 1), adding another layer of safety.

Table 1. Results from tensile testing campaign for Case Studies 1 and 2.

\begin{tabular}{ccccc}
\hline \multicolumn{2}{c}{ Build Orientation } & Ultimate Strength (MPa) & Yield Strength (MPa) & \% Elongation \\
\hline \multirow{2}{*}{ Horizontal } & Average & 392.98 & 244.93 & 6.60 \\
& Std. Dev. & 8.30 & 7.85 & 0.55 \\
\hline \multirow{2}{*}{ Vertical } & Average & 394.29 & 208.54 & 5.5 \\
& Std. Dev. & 1.63 & 2.24 & 0.58 \\
\hline
\end{tabular}


Applying Equation (1), with $\sigma_{\text {vonMises }}$ equal to $110 \mathrm{MPa}, S F_{\text {yield }}$ equal to $1.1, S F_{A M}=1.5$, and $\sigma_{\text {allww }}$, Alsi10Mg $=190 \mathrm{MPa}$, yields a MoS of 0.05. It should be reiterated, however, that this Margin of Safety includes a somewhat arbitrary Safety Factor for Additive Manufacturing equal to 1.5 that has been added in this study to alleviate fears for this new technology. It is felt that this additional safety factor will evolve to values that are closer to 1.0 in the future.

The topologically optimized design is pictured in Figure 8. It can be seen that the optimized design represents a radical departure from the original bracket design, as the only fixed geometrical design constraints pertain to the attachment points between the bracket and the satellite panel and those between the bracket and the camera.

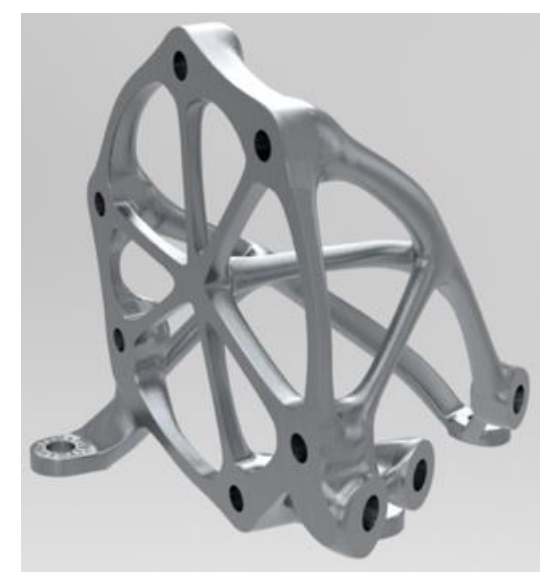

Figure 8. Final Optimization design.

The camera bracket design that is rendered in Figure 8 illustrates the benefits of Additive Manufacturing coupled with topology optimization. Its weight is $89 \mathrm{~g}$ as compared to $425 \mathrm{~g}$ for the heritage part, and the design took approximately two weeks to complete its design. The heritage part was manufactured out of Titanium. Based on the analysis carried out in this work, the heritage part appears to be over-engineered, as the loading and boundary conditions can be satisfied with an aluminum alloy component. Note that no finite element analysis was conducted on the heritage part.

The authors are hard-pressed to envision the design of the bracket pictured without the tools implemented in this work, and furthermore, even if the design were conceived, it would be extremely difficult (if even possible) and costly to manufacture with traditional subtractive methods.

\subsubsection{Manufacturing}

Figure 9 illustrates the build plate as is sits in the EOS M290 Additive Manufacturing platform after fabrication and after powder removal. It should be noted that the support structures are minimal. Visible are five vertical and five horizontal tensile specimens that were fabricated with the components, pyramid thin-walled powder archival vessels, and density cubes for evaluation. Figure 10 illustrates the as-built camera star bracket prior to machining of mating surfaces and attachment points. The circular hole pattern, as well as the other attachment points are to be machined in order to achieve their required tolerances.

\subsubsection{Testing}

The next step in the holistic process flow is testing. The tensile coupons were tested for Ultimate Tensile Strength, Yield Strength, Elongation according to ASTM standard E8, and the density cubes were evaluated via ASTM standard E 562 for microstructure and density. The results are illustrated in Table 1 and are well within the design allowables. Table 1 represents data from two build plates with 10 vertical and 10 horizontal tensile coupons, and six density cubes. 


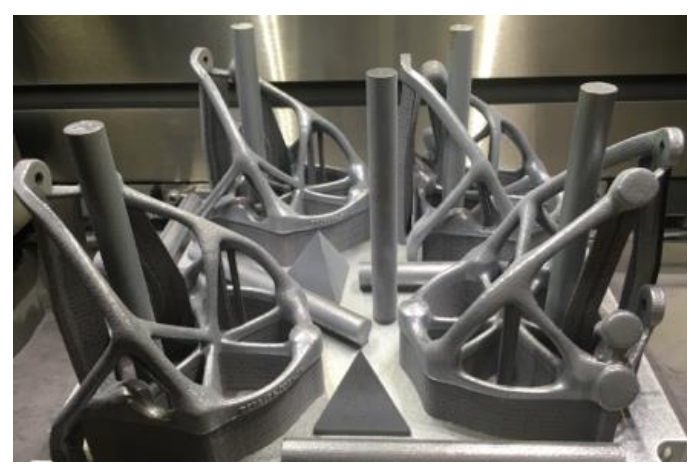

Figure 9. Build plate with 4star tracker camera bracket components.

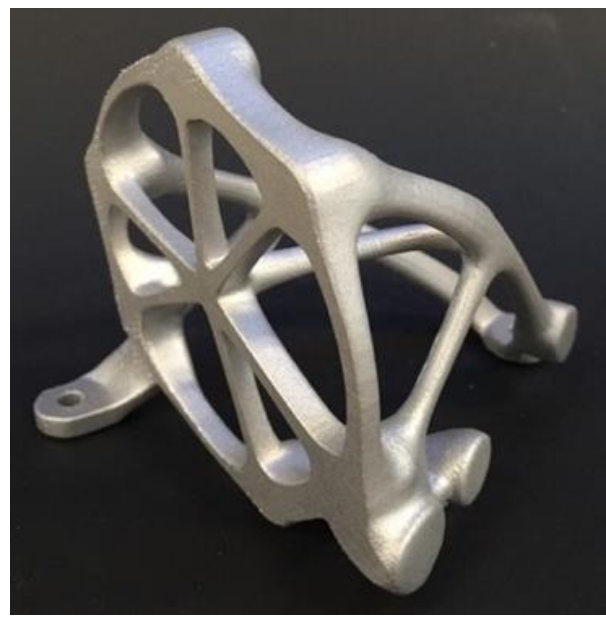

Figure 10. AM fabricated camera star bracket.

On a component level, the components were subjected to the testing campaign sketched in Figure 11. All results were exceptional.

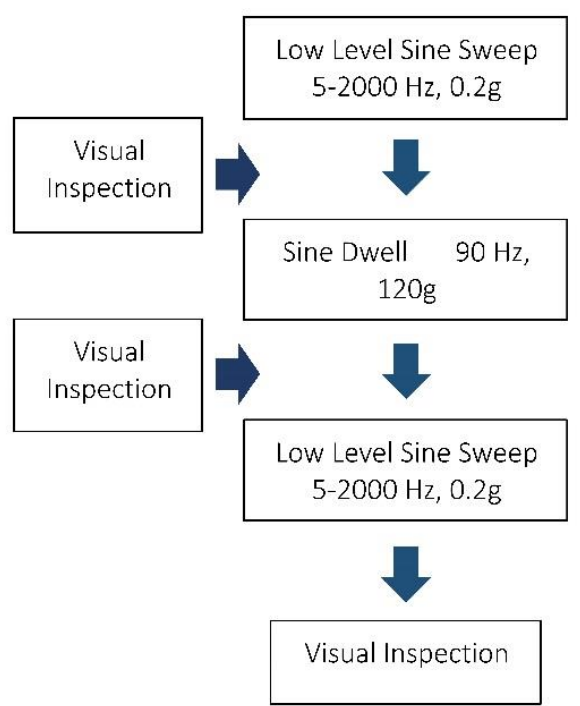

Figure 11. Structural testing flow.

In addition to structurally testing the components, they were each CT scanned and no internal pores, inclusion, or cracks were identified within the applied resolution of the CT scanner. The components were scanned with a resolution of 120 microns, hence it is important to note that 
defects that are smaller than 120 microns may exist but were undetectable with the CT modality. The CT scan was incorporated into the process flow as a risk-mitigation and process control check.

A 3D model was created from the Computed Tomography data of the printed part and compared to the CAD file from which it was printed. Overlapping the two files allows for the generation of heat maps in order to obtain a visual representation of the deviations of the fabricated component from the ideal geometry. The heat map is illustrated in Figure 12. It was found that the printed artifacts exhibited a tendency for small deviations on the downward facing edges with respect to the build direction, which can be attributed to the Additive Manufacturing process. This is because the downward facing edges are in direct contact with powder as opposed to solid, and powder is a less efficient thermal conductor than solid, resulting in significantly different heat transfer attributes between the down facing surfaces and the up facing surfaces. The maximum deviations between the Additively Manufactured part and the CAD data was measured to be under 280 microns. It is also noteworthy that the components were not required to be heat treated, as the measured deviations were within the design allowables specified by the customer. It is possible that a portion of the measured deviations are due to internal residual stresses in combination with the rougher downskin surfaces inherent to powder bed laser fusion. Hence, heat treatment may reduce the geometric deviations, however heat treatment will also be associated with reductions in ultimate and yield strength.

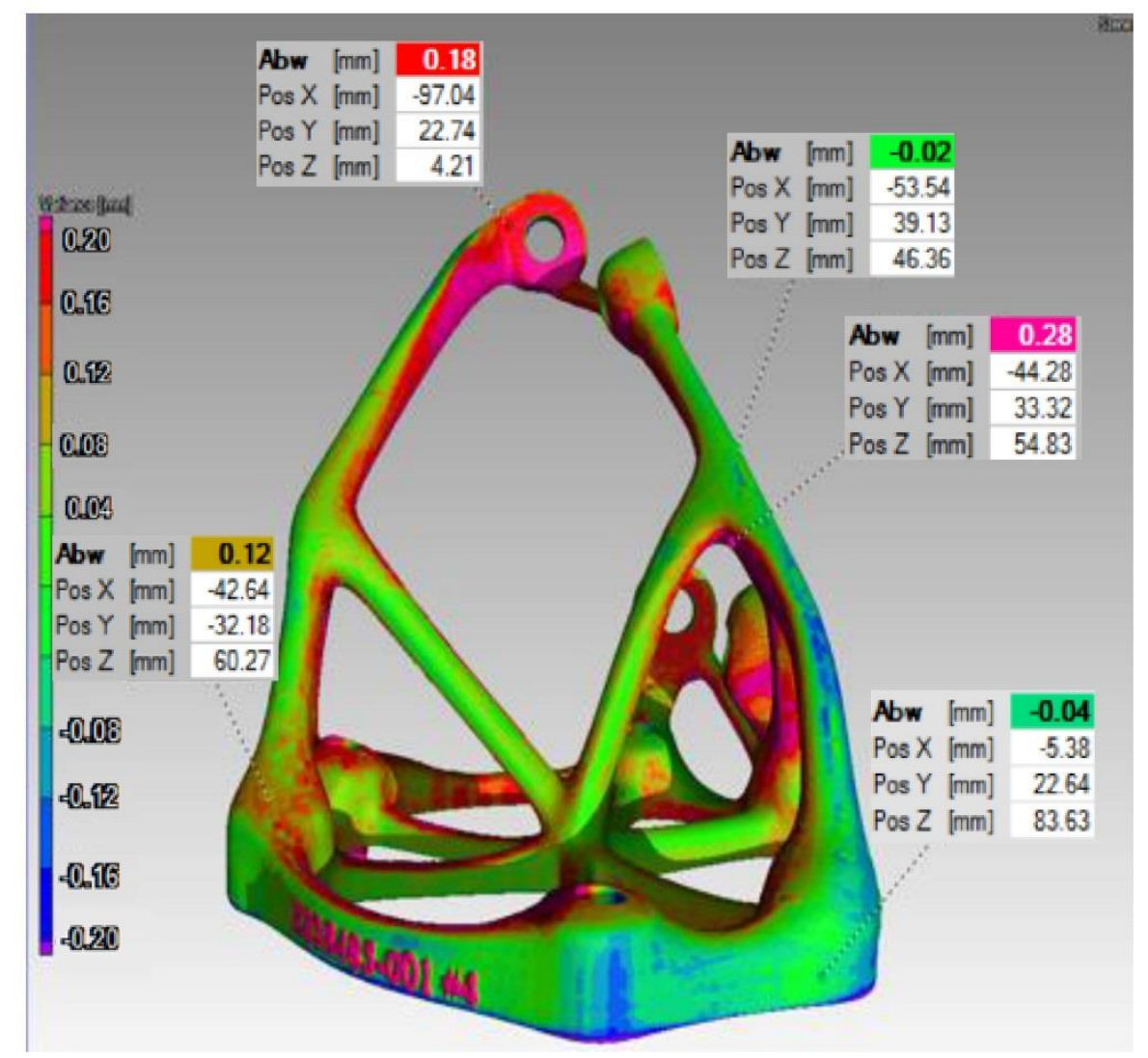

Figure 12. Overlay of nominal CAD geometry with fabricated part geometry obtained from CT scan data.

\subsubsection{Case 1 Summary}

The heritage and traditionally fabricated star tracker bracket illustrated in Figure 3 weighed $425 \mathrm{~g}$ and was machined out of Titanium. The topologically optimized component weighed $89 \mathrm{~g}$ and it was Additively Manufactured out of ALSi10Mg. Both were designed to withstand the same loading conditions and satisfy the same boundary conditions. Furthermore, the entire process, including: 
topology optimization, fabrication, coupon, and component testing took only eight weeks, illustrating that significant lightweighting can be achieved on heritage parts in a rapid timeframe.

\subsection{Case Study 2: SSTL Edge Insert}

Case Study 2 provides the example in which the external boundaries must remain fixed, however material is free to move within the space in order to support the loading conditions.

\subsubsection{Topology Optimization}

Because the edge inserts are press fit into an opening of a satellite sandwich panel (with overall panel dimensions of $250 \times 70 \mathrm{~mm}$ ), the external boundaries of the inserts must remain fixed, as illustrated in Figure 4.

A $3 \mathrm{~mm}$ distance around each attachment point was considered to be fixed and 'non-design space', as well as $3 \mathrm{~mm}$ thickness for all of the orthogonal faces. Because it is anticipated that material will be displaced in the internal space within the external walls, methods to remove unmelted powder were incorporated into the design. Additionally, a build direction was selected so that proper structures can be incorporated to support horizontally built surfaces. The choice of build direction that is indicated in Figure 13 requires that the long horizontal surface be internally supported.

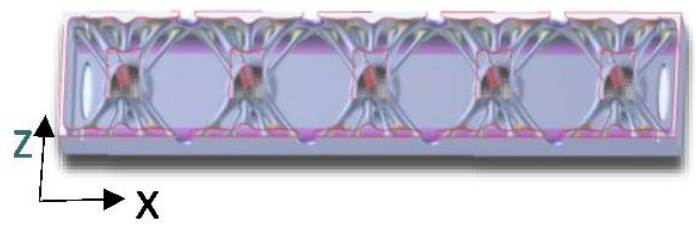

Figure 13. Schematic the edge insert cross section illustrating the macro-lattice supporting the top horizontal surface.

Several different design possibilities were explored and are discussed elsewhere [22]. The final design that is pictured in Figure 13 reveals an internal macro-lattice structure that is designed to support the long horizontal surface. The branch like structures are five across and three deep. Also incorporated are two holes on both ends of the insert for powder removal and serve to equilibrate the internal and external pressure of the structure; a necessity that is required for hardware entering the rarefied environment of space. Other than the supportive branches shown, the insert is hollow, leading to a significant decrease in weight.

\subsubsection{FEM Design Verification}

The sandwich panel in which the insert fits was modeled with two-dimensional (2D) shell elements for the face sheets and 3D elements for the core. The insert is connected to the face sheet and to the core via coincident nodes. The boundary conditions are that all cut faces of the sandwich panel (except for the top and bottom face and face where the insert is embedded) are simply supported (constraining DOF123). The edge inserts were only subject to the following static load cases on each of the five bolts: a force in the $x$ direction (in-plane) of $225 \mathrm{~N}$ and in out-of-plane (Z) direction a force of $355 \mathrm{~N}$.

Figure 14 illustrates the FEA results for the edge attachment. The maximum von Mises stress of $72.7 \mathrm{MPa}$ was identified at the opening port (shown in red) that allows for pressure venting and powder removal, and it is due to the geometrical arrangement. The maximum von Mises stress in the branch like structure was less than $60 \mathrm{MPa}$, both of which are well below the design allowables. Applying Equation (1), with $\sigma_{\text {vonMises }}$ equal to $72.7 \mathrm{MPa}, S F_{\text {yield }}$ equal to 1.1, $S F_{A M}=1.5$, and $\sigma_{\text {allw }}$, Alsi10Mg $=190 \mathrm{MPa}$, yields a MoS of 0.58. It is important to note that the calculated margin or safety also includes an AM safety factor of 1.5 to satisfy industrial concerns. 


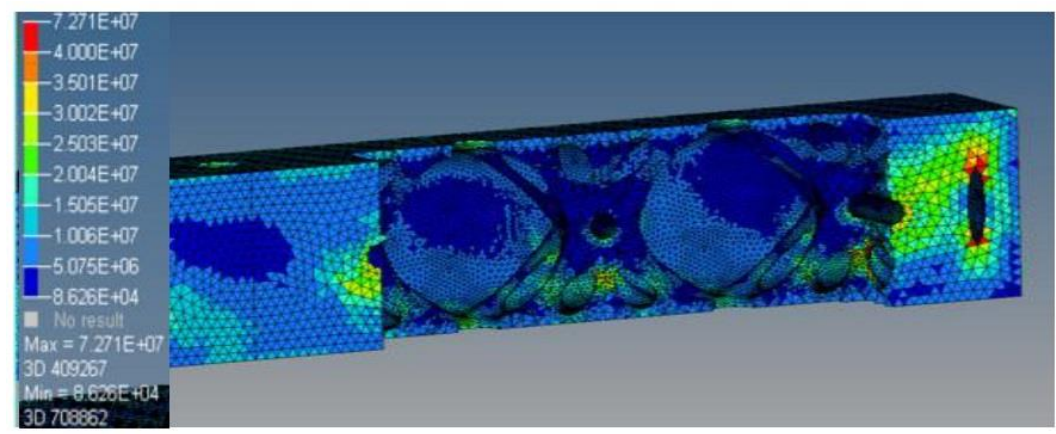

Figure 14. FEA results of Edge Insert.

\subsubsection{Manufacturing and Testing}

The inserts and camera star bracket were manufactured together with the same in-process test coupons. Hence, the mechanical results that are provided above in Table 1 also apply to Case Study 2. The edge inserts were not tested as a part of this project as they were tested on a system level by the customer. Unfortunately, the authors do not have access to the satellite system testing data. The tensile results in Table 1 were a product of 10 vertical and 10 horizontal tensile coupons over two builds. The final sectioned component is pictured in Figure 15.

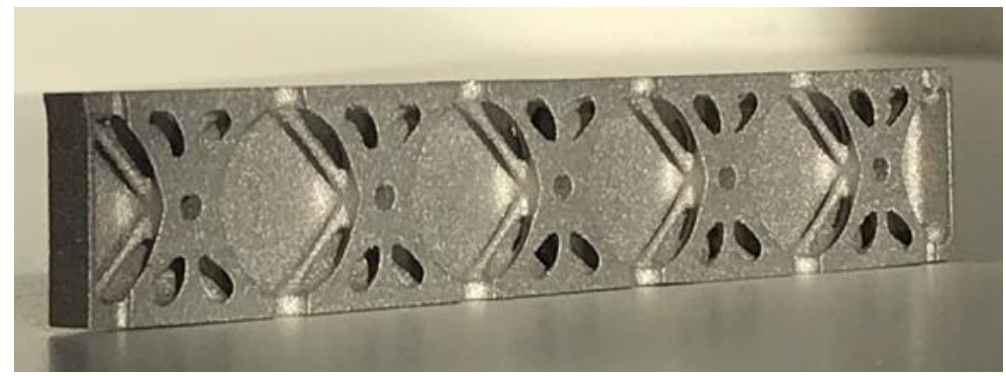

Figure 15. As-printed image of the sectioned Edge insert.

\subsubsection{Case 2 Summary}

The topologically optimized edge insert experienced a $40 \%$ reduction in weight over the heritage solid counterpart. Its design was guided in part by its build orientation, the need to be self-supporting, and the necessity of removing unsintered powder.

\subsection{Case Study 3: Lunar Lander Engine Mount}

Case Study 3, as pictured in Figure 5, provides an illustrative example of topology optimization of a system of large components.

\subsubsection{Topology Optimization}

Preliminary explorations of the topology optimization exercise indicated that in order to satisfy the loading and stiffness requirements, the solid legs of the original nominal design (Figure 5) tended to split into three separate branches, each of which attached to the central hub. It was also discovered that the optimization routine sought solutions in which the branch type structures attached to the central hub at two elevations, arranged as far as possible from each other. Hence, it was decided to explore this avenue of topology optimization and to study whether this solution was mechanically viable. These results also enabled a reduction of the design volume in further optimization runs for the sake of computational effort and for the assessment of the viability of certain design solutions. The design space (gray shaded region) for the topological optimization exercise of the lunar launcher engine mount and the preliminary optimization result that fulfills the strength and stiffness requirements is 
illustrated in Figures 16 and 17. Figure 16 is the top view illustrating how each leg is now formed as three branches and Figure 17 is the isometric image illustrating how the legs attach to the central hub. The apparent discontinuities in the solution are due to the density sensitivity chosen for the image.

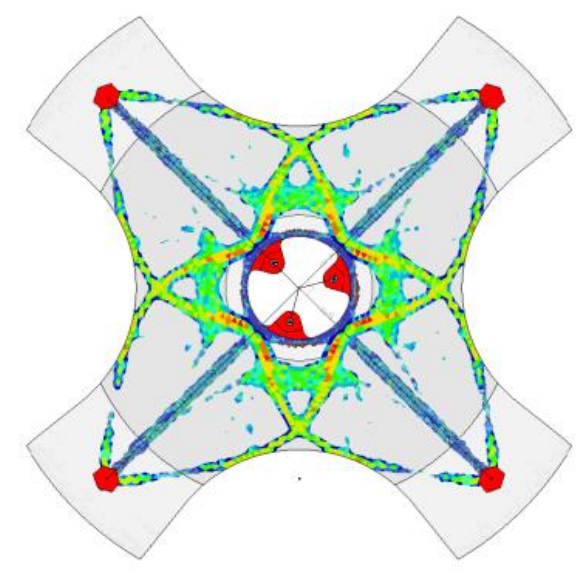

Figure 16. Top design space (gray shaded region) and initial topology optimization result.

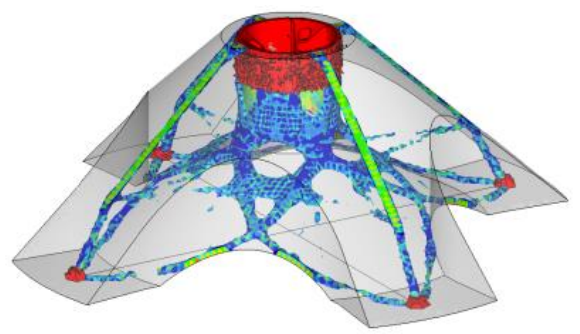

Figure 17. Iso view of design space (gray shaded region) and initial topology optimization result.

These initial studies were focused around the topology optimization of one integrated component that includes the connected legs and hub, with the understanding that once the topology optimization design concept was established, it would be determined where and how to split the components in order to fabricate them. Since the size of the components was a design driving factor, a final topology optimization was performed that incorporated the determined connection points for the legs and the hub and forces the topology optimization to pass through these connections.

An important aspect of the design was to create self-supporting components, or when not possible, components with the minimal number of support structures. Hence, the design was driven in part by component orientation with respect to build direction to ensure minimal support structures. Figure 18 illustrates a rendering of the final design of five split components that are bolted together by close tolerance shear bolts. Each of the components have been designed such that they fit within the build chamber of the EOS M290 machine. Moreover, the legs were designed so that two of them fit together within the dimensions of the build chamber, reducing the number of print jobs to three, consisting of: two plates with two legs each and one with the hub. Additionally, design efforts that are focused on creating approximately uniform member cross sections in an effort to achieve nearly homogeneous heat transfer towards the base plate, thereby minimizing the occurrence of thermal related warping. Furthermore, since downward facing surfaces are known to exhibit inferior characteristics in terms of surface quality and hence dynamic performance, these regions not chosen for highly loaded areas. 


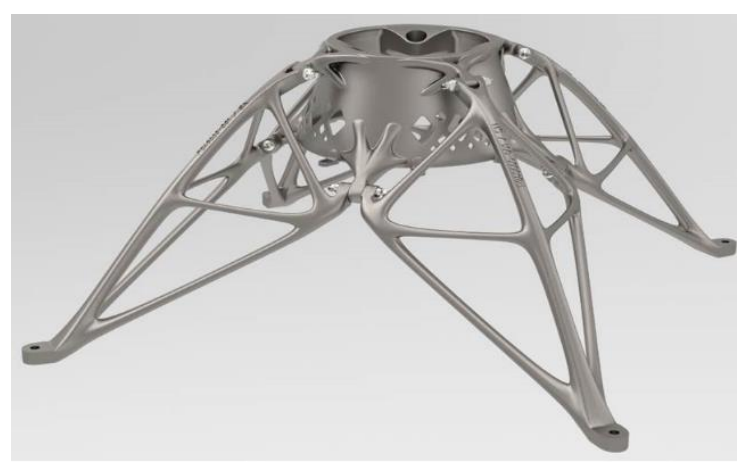

Figure 18. Rendering of final topologically optimized design.

\subsubsection{FEM Design Verification}

Similar to Case Studies 1 and 2, the AM parts are modeled with solid elements (tetra). Integrating components (not shown) that are not additively manufactured are an expansion cone and heat shield, which are modeled using shell elements. The connection of the components was modeled through close tolerance shear bolt connections. More details about the integrating components can be found elsewhere [4]. The engine FE model was created in detail to achieve a modal performance that matches with modal results that were provided by the engine supplier. The integrating heatshield is modeled with larger elements, as it is only used as mass representation.

The engine mounting structure is clamped at all four feet (at the inner bore hole), constraining all translational and rotational degrees of freedom to reflect the mounting to the spacecraft structure. Results from the dynamic testing campaign will be fed back to this step and the settings will be adjusted if necessary in order to correlate the model. The components are connected through close tolerance shear bolt connections. More details of how connections between the structural components were realized in the FE model are provided elsewhere [4].

The structure is subjected to quasi static as well as sine and random vibration loads. Results of the analysis are presented in Figures 19 and 20, which illustrate the stress plots for static equivalent load cases based on the accelerations from the random analysis ( $3 \mathrm{xg}_{\mathrm{RMS}}$ method) in the xy plane and $\mathrm{z}$ planes of the spacecraft, respectively. Enveloping the two load cases, the maximum stress was found to be 111.2 MPa. Using values of $S F_{\text {yield }}$ equal to $1.1, S F_{A M}=1.5$, and $\sigma_{\text {allw, }}$ AlSi10Mg $=190 \mathrm{MPa}$, a MoS of 0.04 is calculated. Hence, all stresses are well within the design allowables for the final optimized concept providing positive margin of safety, and hence according to the holistic process flow, this design is analytically verified and ready to be manufactured. The static equivalent load level for the z-excitation is $154 \mathrm{~g}$ out of plane and $25 \mathrm{~g}$ in plane and $36 \mathrm{~g}$ out of plane and $79 \mathrm{~g}$ in plane for the xy-excitation, respectively. Moreover, fatigue and shock analysis were also performed. Fatigue analysis has been done with the ESA software ESAFATIG v4.3.1a; the fatigue calculations are based on the linear damage accumulation (Palmgren-Miner) rule. The fatigue study required that four times the life needs to be shown, and the analysis resulted in 10.4 times life. The shock assessment was based on the ECSS "Point Source Excitation Method". With a safety factor of $3 \mathrm{~dB}$, a positive margin of $4.3 \mathrm{~dB}$ was determined from the analysis.

\subsubsection{Manufacturing}

As with Case Studies 1 and 2, all components were manufactured in AlSi10Mg on an EOS M290 system at the Morf3D facility. They were fabricated with a 30 micron [1.2 mils] build layer thickness and with a build plate temperature of $165^{\circ} \mathrm{C}\left[329^{\circ} \mathrm{F}\right]$. None of the components required heat treatment due to the design and due to the elevated build temperature. The powder that was used is characterized by the following D values: D50 of 42.78 microns [ 1.7 mils] and D90 of 69.88 microns [ 2.75 mils]. 


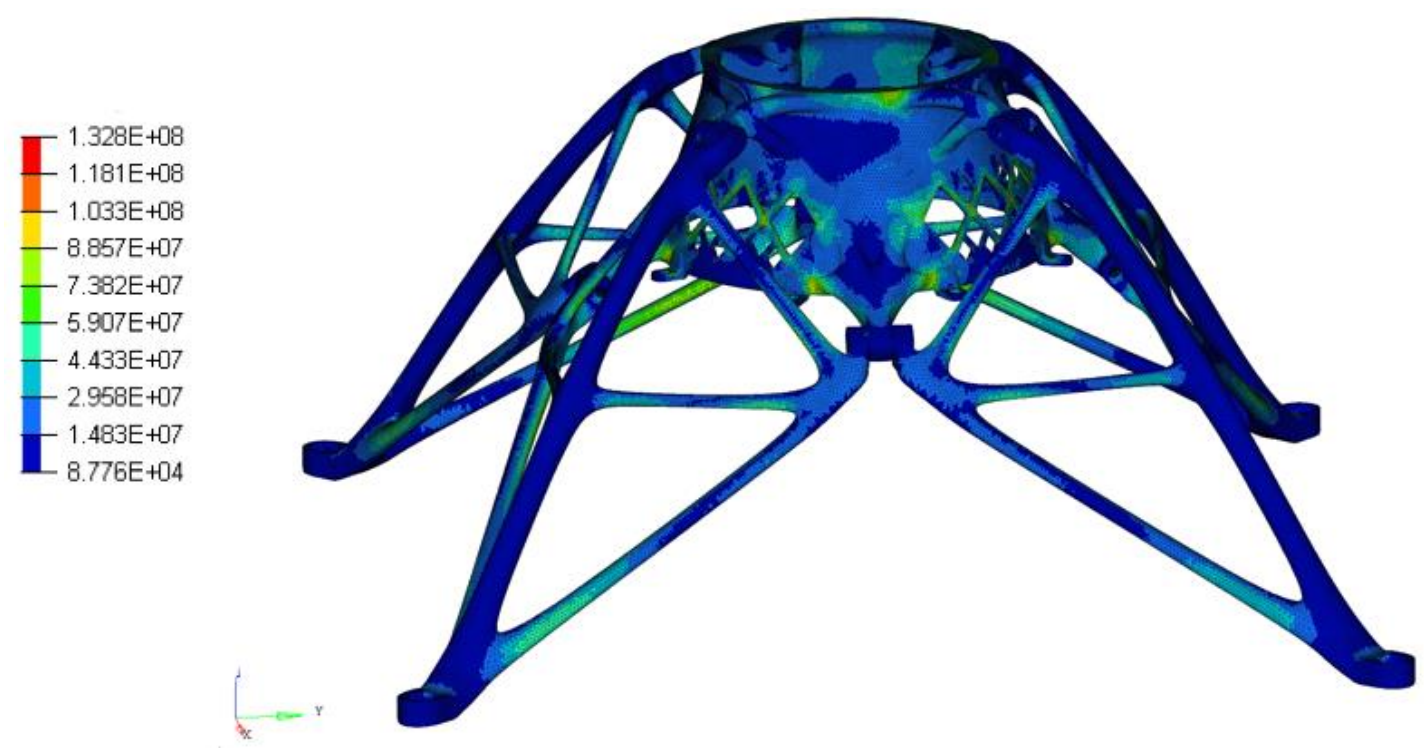

Figure 19. Results of the FEM analysis: Stress plot of the complete engine mount structure subjected to $\mathrm{x} / \mathrm{y}$ excitation.

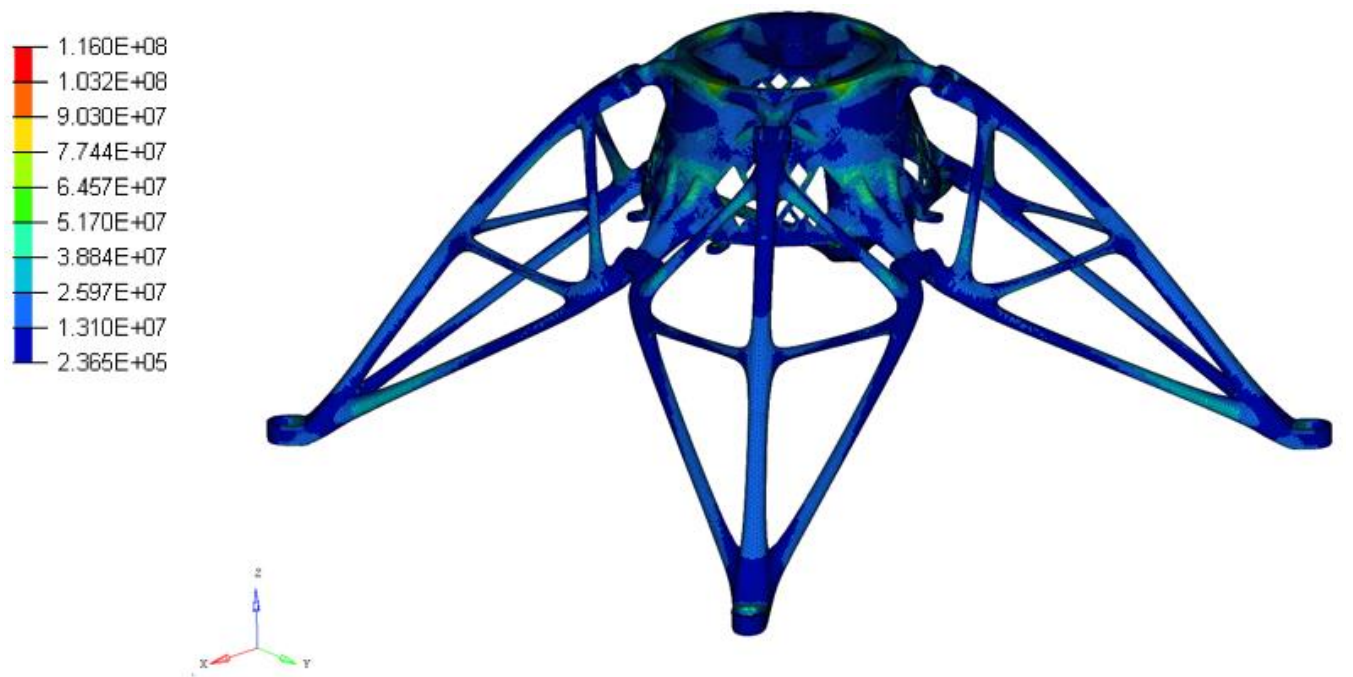

Figure 20. Results of the FEM analysis: Stress plot of the complete engine mount structure subjected to Z excitation.

Figure 21 depicts a photograph of the three build plates that comprise the system. The leftmost plate contains two legs, the center contains the connecting hub, and the rightmost contains the remaining two legs. In-process coupons (tensile and density cubes) were built with each plate along with the aforementioned pyramid powder archival system. The vertical coupons built with the hub were incorporated under the eight tabs around the main circumference that would otherwise require support structures, hence these coupons serve two purposes.

As can be seen in Figure 21, the design succeeds in terms of requiring minimal support structures to support extended overhangs, and it was possible to fabricate two legs simultaneously. After complete powder removal, the parts are removed from the plate with an EDM wire cutter. Hence, supports connecting the parts to the plate must have sufficient height to permit this subtractive removal process from the build plate. 


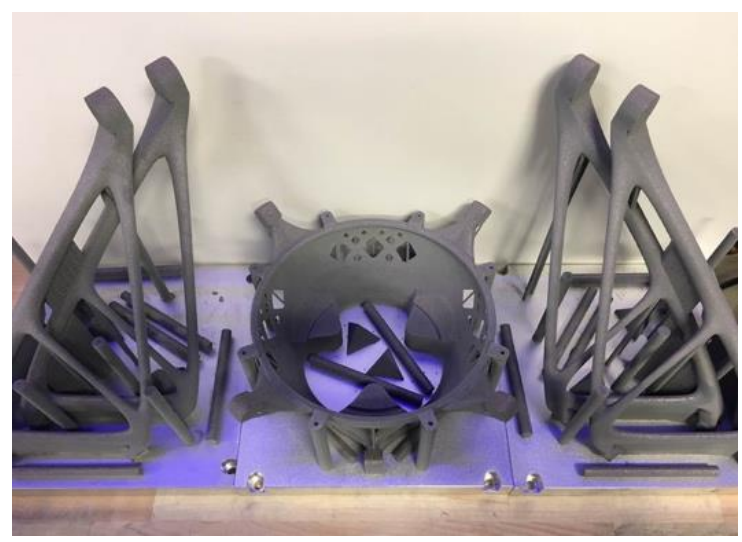

Figure 21. Photograph of three build plates after additive manufacturing.

Post processing included media blasting with glass bead media of 60-120 grit, followed by 70-140 grit. The attachment points of all components were machined to precision mating surfaces. Hence, in addition to designing and fabricating the desired components, it is necessary to design and fabricate jigs and tools for subsequent subtractive machining and testing.

\subsubsection{Testing}

Tensile tests for Case Study 3 are presented in Table 2, and they are comprised of 15 horizontal and 15 vertical coupons. Tested were the Ultimate Tensile Strength, Yield Strength, and Elongation for horizontally and vertically printed tensile coupons. All tensile testing was performed according to ASTM E8 standards. Coupons were fabricated as solid cylinders, as pictured in Figure 20 and machined to the appropriate dog-bone geometry required for testing. All tensile tests were well within the design allowables specified by the customer.

Table 2. Results from tensile testing campaign for Case Study 3.

\begin{tabular}{ccccc}
\hline \multicolumn{2}{c}{ Build Orientation } & Ultimate Strength (MPa) & Yield Strength (MPa) & \% Elongation \\
\hline \multirow{2}{*}{ Horizontal } & Average & 396.2 & 259.6 & 8.1 \\
& Std. Dev. & 7.3 & 7.4 & 0.8 \\
\hline \multirow{2}{*}{ Vertical } & Average & 434.1 & 244.9 & 5.8 \\
& Std. Dev. & 11.8 & 9.0 & 0.7 \\
\hline
\end{tabular}

Additionally, density coupons were evaluated via ASTM standard E 562 and it was found that for each case that the density was greater than $99.7 \%$. Hence, the mechanical and material properties are acceptable and the testing continued on the component level.

Component testing included non-destructive CT scanning, which indicated that no pores, crack, or inclusions were identified within the applied resolution of the CT scanner, which was 150 microns. Hence, pores, cracks, and other flaws smaller than 150 microns may be present in the components. Additionally, as with the previous two test cases, the CT scanned data also yielded 3D models of the components that were compared to the nominal CAD files. Comparison of the actual to nominal hub geometry is illustrated in Figure 22, and that of one representative leg is found in Figure 23. It was found that all components were well within the design tolerances that were established by the customer.

Dynamic structural testing was performed on the assembled system and it included a low level sine sweep on each spacecraft axes as well as high level sine, random, and shock testing. The additively manufactured system of components performed well and they were determined to be structurally sound and suitable for flight. 


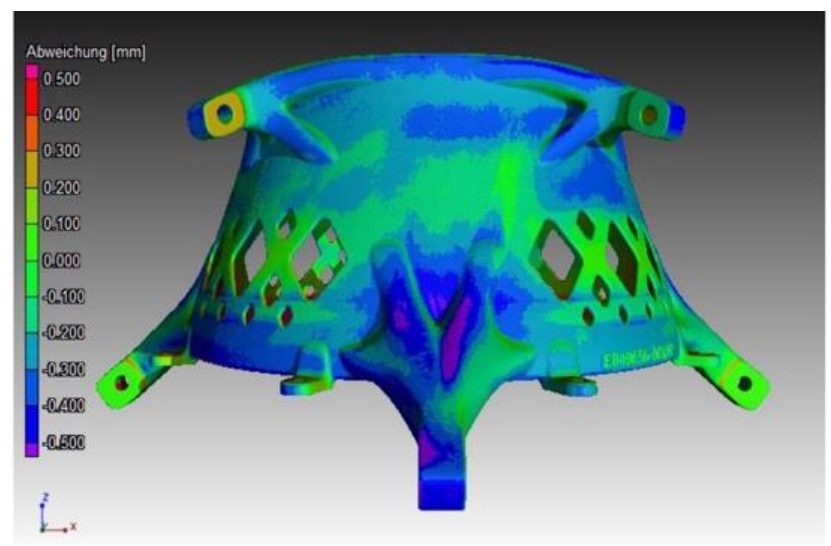

Figure 22. Actual versus nominal comparison of the hub from the CT data.

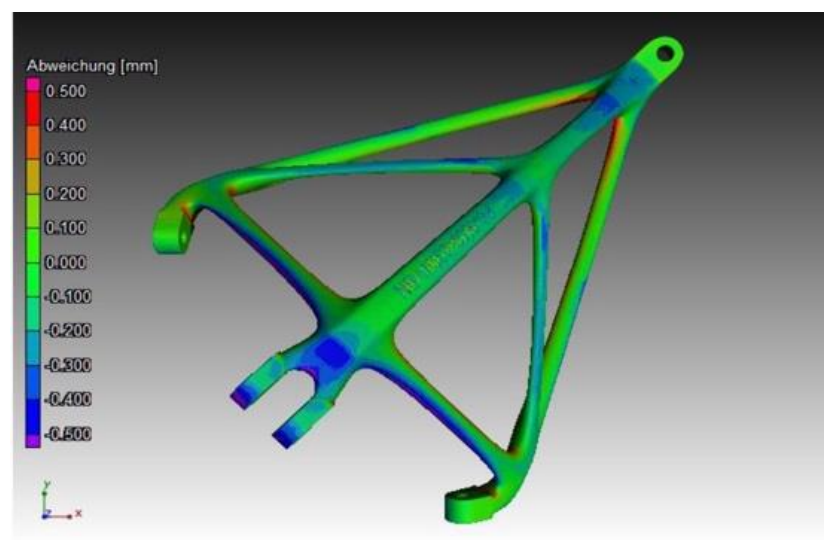

Figure 23. Actual versus nominal comparison of a leg from the CT data.

\subsubsection{Case 3 Summary}

Specific attention has been paid on designing for AM, including topology optimization and design interpretation for AM. Optimization goals included the minimization of component mass while meeting constraints for the first natural frequency as well as the maximum stress limit. Coupled design interpretation considerations addressed the segmentation of the large part into a system of components that fit within the build chamber, and the minimization of support structures.

The resulting system of components include four bionic inspired legs and a central hub that are significantly lighter in weight than the original baseline design (i.e., $2.95 \mathrm{~kg}$ compared to $4.0 \mathrm{~kg}$ ). Note that the nominal un-optimized component and the topologically optimized component are both designated to be fabricated in AlSi10Mg. The weight savings in the topologically optimized component that are shown in Figure 18 is due to the optimization of material placement. In-process test coupons were fabricated with each build and their tested values were well within the design acceptance limits set by the customer. Powder archival units were also fabricated and stored for future interrogation if required. Computed Tomography testing on the component level revealed that the fabricated components were within the geometric design limits and there was negligible porosity, corroborating the density coupon testing at $99.7 \%$.

\section{Summary}

Three case studies were selected to demonstrate the AM holistic process flow. The parts were selected because they qualified as good candidate parts. That is, they found value in reducing the component weight; they demonstrated a rapid fabrication life-cycle (including analysis, fabrication, testing, and certification); their required tolerances were such that they did not require heat treatment. 
The first and possibly most important step in the process flow is the identification of suitable parts for additive manufacturing. Parts that are critically loaded may require a larger margin of safety, and those requiring tighter tolerances may require heat treatment to mitigate warping, or more extensive post-machining processes. Such parts may enjoy less weight savings than those that are presented in this work.

The aim of this work was to demonstrate the value of topology optimization combined with Additive Manufacturing for the fabrication of flight hardware with the aid of three unique case studies. Each case study offered a different example of topology optimization. The first case study permitted significant material re-location within the design space and did not require the incorporation of the exterior boundaries into the design, thereby resulting in an organically shaped component that bears little resemblance to its heritage counterpart and is significantly lighter in weight. The second case study required the preservation of the external boundaries of the design space into the actual design, but it allowed the topology optimization routine to remove a significant amount of material internal to the boundaries. Hence, externally this part resembled its heritage part, however its internal features were not possible to achieve with traditional manufacturing methods. The third case study illustrated a system of five components that worked together to create a lunar lander engine mount. In each case, care was taken to minimize support structures, and when supports were necessary, to ensure that they were accessible for removal. Additionally, care was taken to ensure that downward facing surfaces were not load bearing and for case study 2 , any unmelted powder was readily removable from the component.

It was found in each case that significant weight savings occurred in the topologically optimized version. It should be noted that the particular heritage components that were selected for the presented case studies were susceptible to weight savings through redesign (e.g., the component presented in the first case study need not be fabricated out of Titanium when Aluminum would support the intended application). Future weight savings may not be as significant as the examples presented in this work.

In addition to coupling the design with the build orientation, downstream processes, such as testing and secondary machining, were considered in the design phase so that methods to fixture the resulting geometries in their appropriate jigs were accommodated. The three case studies also demonstrated the efficacy of a holistic process-flow that originates with part selection and includes topology optimization, FEM validation, Additive Manufacturing, mechanical and material testing, and terminates in approving the component for flight. The process flow was successfully demonstrated with three case studies; each of which with different topology optimization requirements. The entire process flow for the first two case studies, from concept to certification, took only eight weeks to complete. The third case study took 16 weeks from concept to certification. The aggressive testing campaign included tensile tests, density testing, CT scanning, and dynamic testing. The Additively Manufactured components passed all testing criteria with comfortable margins, demonstrating that additive manufacturing, when approached with a methodical holistic process flow, is an attractive manufacturing method for creating lightweight, functional metallic components that can be approved or flight.

Author Contributions: Conceptualization, M.F., M.G; I.M., M.O., methodology, M.F., M.G., Resources, I.M., M.G., formal analysis, M.F., investigation, M.O., data curation, M.O., M.G., writing, M.O. project administration, M.O., I.M., M.G.

Funding: This research received no external funding.

Acknowledgments: The author would like to acknowledge Russel Vernon of Altair Engineering for his collaborative efforts on this project regarding topology optimization of Case Study 2. Special thanks are also extended to the executive management team at Electro Optical Systems, EOS GmbH, for their continued support of this work and to Morf3D for their continued support.

Conflicts of Interest: The authors declare o conflicts of interest. 


\section{References}

1. Wohlers, T. Additive Manufacturing and 3D Printing State of the Industry: Wohlers Report; Wohler's Associates, Inc.: Fort Collins, CO, USA, 2016.

2. Zhai, Y.; Lados, D.; Lagoy, J. Additive Manufacturing: Making Imagination the Major Limitation. JOM 2014, 6, 808-816. [CrossRef]

3. Orme, M.; Gschweitl, M.; Ferarri, M.; Vernon, R.; Madera, I.; Yancey, R.; Mouriaux, F. Additive Manufacturing of Lightweight, Optimized, Metallic Components Suitable for Space Flight. AIAA J. Spacecr. Rocket. 2017, 54, 1050-1059. [CrossRef]

4. Orme, M.; Gschweitl, M.; Ferrari, M.; Madera, I.; Mouriaux, F. Designing for Additive Manufacturing: Lightweighting Through Topology Optimization Enables Lunar Spacecraft. J. Mech. Des. 2017. [CrossRef]

5. Deckard, C.; Beaman, J.; Darrah, J.F. Method for Selective Laser Sintering with Layerwise Cross-Scanning. U.S. Patent US 5155324 A, 13 October 1986.

6. Horn, T.; Harrysson, O. Overview of current additive manufacturing technologies and selected applications. Sci. Rev. 2012, 95, 255-282. [CrossRef]

7. Agarwala, M.; Bourell, D.; Beaman, J.; Marcus, H.; Barlow, J. Direct selective laser sintering of metals. Rapid Prototyp. J. 1995, 1, 26-36. [CrossRef]

8. Das, S. Physical Aspects of Process Control in Selective Laser Sintering of Metals. Adv. Eng. Mater. 2003, 5, 701-711. [CrossRef]

9. Slotwinski, J.A.; Garboczi, E.J.; Stutzman, P.E.; Ferraris, C.F.; Watson, S.S.; Peltz, A.M.A. Characterization of Metal Powders Used for Additive Manufacturing. J. Res. Natl. Inst. Stand. Technol. 2014, 119, 460-493. [CrossRef] [PubMed]

10. Frazier, W. Metal Additive Manufacturing: A review. J. Mater. Eng. Perform. 2014, 23, 1917-1928. [CrossRef]

11. Herzog, D.; Seyda, V.; Wycisk, E.; Emmelmann, C. Additive manufacturing of metals. Acta Mater. 2016, 117, 371-392. [CrossRef]

12. Louvis, E.; Fox, P.; Sutcliffe, C. Selective laser melting of aluminum components. J. Mater. Process. Technol. 2010, 211, 275-284. [CrossRef]

13. Olakanmi, E.; Cochrane, R.; Dalgarno, W. A review on selective laser sintering/melting (SLS/SLM) of aluminum alloy powders: Processing, microstructure, and properties. Progr. Mater. Sci. 2015, 74, 401-477. [CrossRef]

14. Sercomb, T.B.; Li, X. Selective laser melting of aluminum and aluminum metal matrix composites: Review. Mater. Technol. 2016, 31, 77-85.

15. Song, B.; Zhao, X.; Li, S.; Han, C.; Wei, Q.; Wen, S.; Liu, J.; Shi, Y. Differences in microstructure and properties between selective laser melting and traditional manufacturing for fabrication of metal parts; A review. Front. Mech. Eng. 2015, 10, 111-125. [CrossRef]

16. Trevisan, F.; Calignano, F.; Lorusso, M.; Pakkanen, J.; Aversa, A.; Ambrosio, E.P.; Lombardi, M.; Fino, P.; Manfredi, D. On the Selective Laser Melting (SLM) of the AlSi10Mg Alloy: Process, Microstructure, and Mechanical Properties. Materials 2017, 10, 76. [CrossRef] [PubMed]

17. Kempen, K.; Thijs, L.; Van Humbeeck, J.; Kruth, J.-P. Mechanical properties of ALSi10Mg produced by Selective Laser Melting. Phys. Procedia 2012, 39, 439-446. [CrossRef]

18. Prashanth, K.; Scudino, S.; Klauss, H.; Surreddi, K.; Lober, L.; Wang, Z.; Chaubey, A.; Kuhn, U.; Eckert, J. Microstructure and mechanical properties of Al-12Si produced by selective laser melting: Effect of heat treatment. Mater. Sci. Eng. A 2014, 590, 153-160. [CrossRef]

19. Vranken, B.; Thijs, L.; Kruth, J.-P.; Humbeeck, J.V. Heat treatment of Ti6Al4V produced by Selective Laser Melting; Microstructure and mechanical properties. J. Alloys Compd. 2012, 541, 117-185. [CrossRef]

20. Li, W.; Shuai, L.; Liu, J.; Zhang, A.; Zhou, Y.; Wei, W.; Yan, C.; Shi, Y. Effect of heat treatment on AlSi10Mg alloy fabricated by selective laser melting: Microstructure evolution, mechncial properties and fracture mechanism. Mater. Sci. Eng. A 2016, 663, 116-125. [CrossRef]

21. Aboulkhair, N.; Everitt, N.; Ashcroft, I.; Tuck, C. Reducing porosity in AlSi10Mg parts processed by selective laser melting. Addit. Manuf. 2014, 1, 77-86. [CrossRef]

22. Orme, M.; Gschweitl, M.; Vernon, R.; Ferrari, M.; Madera, I.; Yancey, R.; Mouriaux, F. A Demonstration of Additive Manufacturin as an Enabling Technology for Rapid Satellite Design and Fabrication. In Proceedings of the SAMPE, Long Beach, CA, USA, 23-26 May 2016. 
23. Rozvany, G. Topology Optimization in Structural Mechanics; CISM International Centre for Mechanical Sciences; Springer: Berlin, Germany, 1997; p. 322.

24. Brennan, J. 20 Years of Topology Optimization: Birth and Maturation of a Disruptive Technology. 2015. Available online: http:/ /insider.altairhyperworks.com/20-years-topology-optimization-birth-maturationdisruptive-technology/ (accessed on 27 January 2017).

25. Bracket, D.; Ashcroft, I.; Hague, R. Topology Optimization for Additive Manufacturing. In Proceedings of the Solid Freeform Fabrication Symposium, Austin, TX, USA, 17 August 2011.

26. Sigmund, O. On the usefulness of non-gradient approaches in topology optimization. Struct. Multidiscip. Optim. 2011, 43, 589-596. [CrossRef]

27. Yan, C.; Hao, L.; Hussein, A.; Bubb, S.L.; Young, P.; Raymont, D. Evaluation of light-weight AlSi10Mg periodic cellular lattice structures fabricaated via direct metal laser sintering. J. Mater. Process. Technol. 2014, 214, 856-864. [CrossRef]

28. Langelaar, M. Topology optimization of 3D self-supporting structures for additive manufacturing. Addit. Manuf. 2016, 12, 60-70. [CrossRef]

29. Mirzendehdel, A.M.; Krishnan, S. Support structure constrained topology optimization for additive manufacturing. Comput.-Aided Des. 2016, 81, 1-13. [CrossRef]

30. Allaire, G.; Dapogny, C.; Estevez, R.; Faure, A.; Michailidis, G. Structural optimization under overhang constraints imposed by additve manufacturing technologies. J. Comput. Phys. 2017, 351, 295-328. [CrossRef]

31. Guo, X.; Zhou, J.; Zhang, W.; Du, Z.; Liu, C.; Liu, Y. Self-supporting strucutre design in additive manufacturing through explicit topology optimiation. Comput. Methods Appl. Mech. Eng. 2017, 323, 27-63. [CrossRef]

32. Wang, Y.; Gao, J.; Kang, Z. Level set-based topology optimization with overhang constraing: Towards support-free additive manufacturing. Comput. Methods Appl. Mech. Eng. 2018, 329, 591-614. [CrossRef]

33. Mhapsekar, K.; McConaha, M.; Anand, S. Additive Manufacturing Constraints in Topology Optimization for Improved Manufacturability. J. Manuf. Sci. Eng. 2018, 140, 051017. [CrossRef]

34. Garaigordobil, A.; Ansola, R.; Santamaria, J.; Fernandez de Bustos, I. A new overhang constraint for topology optimization of self-supporting structures in additive manufacturing. Struct. Multidicip. Optim. 2018, 58, 2003-2017. [CrossRef]

35. Jankovics, D.; Gohari, H.; Tayefeh, M.; Barari, A. Developing Topology Optimization with Additive Manufacturing Constraints in ANSYS ${ }^{\circledR}$. IFAC Pap. OnLine 2018, 51, 1359-1364. [CrossRef]

36. Mezzadri, F.; Bouriakov, V.; Qian, X. Topology optimization of self-supporting suport structures for additive manufacturin. Addit. Manuf. 2018, 21, 666-682. [CrossRef]

37. Liu, J.; Gaynor, A.; Chen, S.; Kang, Z.; Suresh, K.; Takezawa, A.; Li, L.; Kato, J.; Tang, J.; Want, C.; et al. Current and future rends in topology optimizatin for additive manufacturing. Struct. Multidiscip. Optim. 2018, 57, 2457-2483. [CrossRef]

(C) 2018 by the authors. Licensee MDPI, Basel, Switzerland. This article is an open access article distributed under the terms and conditions of the Creative Commons Attribution (CC BY) license (http://creativecommons.org/licenses/by/4.0/). 